\title{
Restorasi mahkota pasak pada gigi dengan jarak serviko-oklusal pendek Dowel crown restoration on tooth with short cervico-occlusal distance
}

\author{
${ }^{1}$ Setyawan Bonifacius, ${ }^{2}$ Sri Wahyuningsih Rais \\ ${ }^{1}$ Bagian Prostodonsia Fakultas Kedokteran Gigi Universitas Padjajaran, Bandung \\ ${ }^{2}$ Bagian Prostodonti Program Studi Kedokteran Gigi Fakultas Kedokteran Universitas Sriwijaya, Palembang \\ Indonesia
}

\begin{abstract}
Dowel crown restoration is a restoration which is often performed by dentists in daily practice. Dental crowns require the dowel crown restoration due to several factors including the crown damage cause has been very severe. Dowel crown restoration usually consists of two parts, namely dowel with core and crown restoration on it. The core must be high enough in cervico-occlusal direction to obtain sufficient retention for the attachment of the crown. In some cases this condition cannot be fulfilled because the cervico-occlusal distances are too short resulting from extrusion of the tooth. This paper is reporting a case of management tooth maxillary second premolar with limited cervico-occlusal dimension with dowel crown restoration in one unit. The technique was a combination of direct and indirect method. The result was an accurate and retentive dowel crown, and has a good aesthetic.
\end{abstract}

Key words: one unit construction, casting dowel, dowel crown

\begin{abstract}
ABSTRAK
Perawatan dengan mahkota pasak merupakan salah satu restorasi yang sering dilakukan oleh para dokter gigi dalam praktek sehari-hari. Gigi memerlukan restorasi mahkota pasak karena beberapa faktor penyebab di antaranya kerusakan mahkota yang sudah sangat parah. Restorasi mahkota pasak biasanya terdiri dari dua bagian, yaitu pasak berikut intinya dan restorasi mahkota di atasnya. Inti harus cukup tinggi dalam arah serviko-oklusal untuk mendapatkan retensi yang cukup bagi perlekatan mahkota di atasnya.Pada beberapa kasus hal ini tidak dapat dipenuhi karena jarak servikooklusal gigi yang pendek akibat pergerakan ekstrusi. Pada artikel laporam kasus ini akan dibahas tentang pembuatan restorasi mahkota pasak pada gigi premolar kedua rahang atas yang jarak serviko-oklusalnya pendek. Berbeda dengan cara yang biasa, pada kasus ini dihasilkan suatu restorasi mahkota pasak tuang yang dikonstruksi satu unit. Teknik pembuatannya merupakan kombinasi antara teknik direct dan indirect. Dengan cara ini dihasilkan suatu restorasi mahkota pasak yang akurat, retentif dan nilai estetik yang baik.
\end{abstract}

Kata kunci: konstruksi satu unit, pasak tuang, mahkota pasak

Koresponden: Setyawan Bonifacius, Komplek Pasirlayung Asri Blok A6, Kel. Pasirlayung, Kec.Cibeunying Kidul, Bandung, Indonesia. E-mail: prosto.fkg@unpad.ac.id

\section{PENDAHULUAN}

Perawatan dengan mahkota pasak merupakan salah satu jenis restorasiyang sering dilakukan dalam praktek dokter gigi sehari-hari. Gigi memerlukan restorasi mahkota pasak biasanya karena kerusakan yang cukup luas dan memerlukan perawatan saluran akar, sehingga dikhawatirkan tidak cukup kuat jika hanya ditambal atau hanya dibuatkan mahkota jaket. Pemasangan mahkota jaket pada gigi non-vital merupakan tindakan yang tidak tepat karena adanya peningkatan kerapuhan dentin dan karena hilangya dentin pendukung akibat akses yang diperlukan untuk perawatan saluran akar. Pada situasi demikian mahkota pasak merupakan perawatan pilihan yang baik. ${ }^{1}$

Martanto menyatakan bahwa struktur mahkota gigi-gigi anterior yang telah mengalami perawatan saluran akar melemah karena kontinuitas dentin terputus akibat pembuangan jaringan di permukaan lingual saat perawatan atau karena adanya karies yang besar sehingga dentin akan menjadi rapuh.
Gigi posterior non vital yang telah mengalami kerusakan berat, restorasinya sering menjadi sulit, jika ruangan mahkota memendek karena ekstrusi gigi antagonis. Penggantian konvensional dengan membuat mahkota penuh yang disemen pada suatu inti berpasak seringkali gagal oleh karena ruangan yang sedemikian pendek itu, tidak memungkinkan pembuatan inti yang dapat memberikan pegangan yang cukup pada mahkota. ${ }^{2}$

Artikel laporan kasus ini membahas mengenai pembuatan restorasi mahkota pasak pada gigi premolar kedua rahang atas dengan ruang servikooklusal pendek. Pada kasus ini restorasi dibuat menggunakan desain mahkota pasak konstruksi satu unit, dengan teknik pembuatan pola mahkota pasak secara direct-indirect.

\section{KASUS}

Seorang pasien perempuan usia 26 tahun datang ke klinik gigi dengan keluhan mahkota gigi premolar dua rahang atas patah. Pemeriksaan klinis 

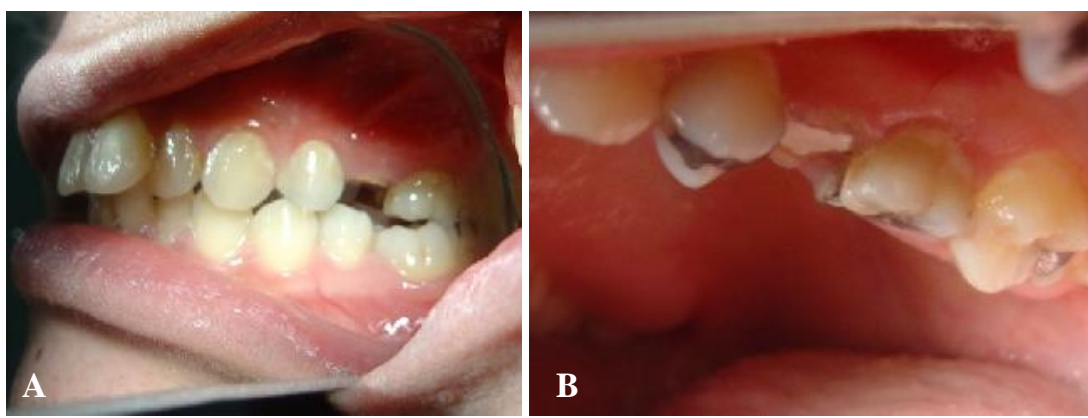

Gambar 1 Kondisi awal gigi pasien; A aspek bukal, B aspek palatinal
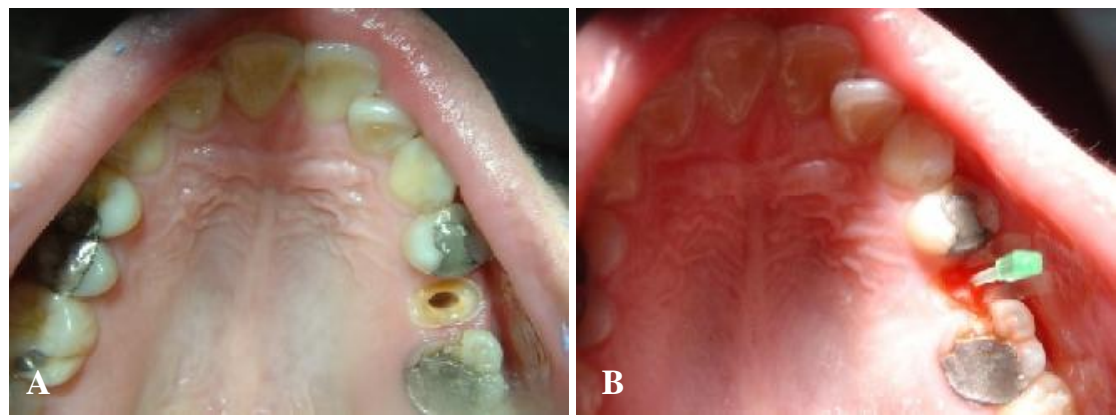

Gambar 2A Preparasi saluran akar, B pembuatan pola pasak dari pin plastik dan resin otopolimerisasi.
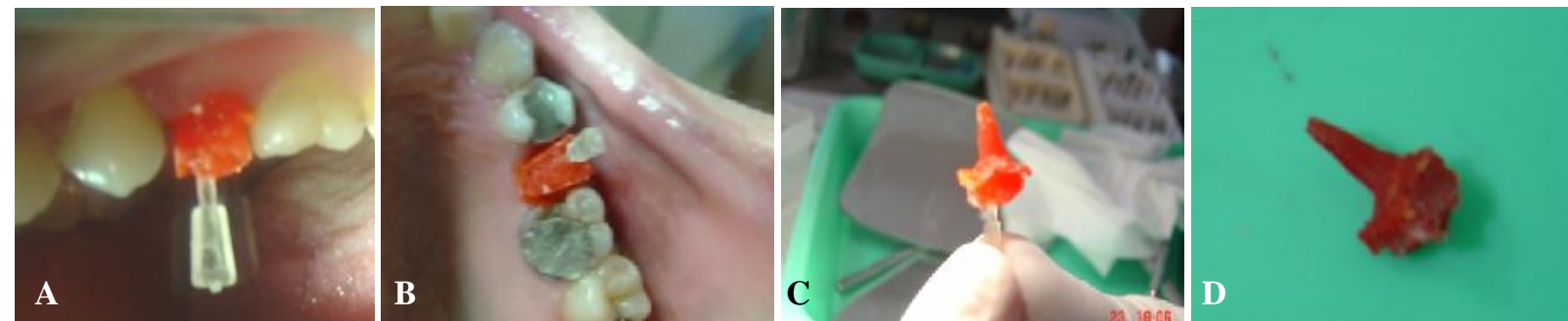

Gambar 3A,B Penambahan resin otopolimerisasi pada bagian korona; C,D pola pasak setelah dikeluarkan dari saluran akar.

menunjukkan gigi 25 telah non-vital dengan jarak serviko-oklusal relatif pendek.Pasien menginginkan gigi tersebut dipertahankan dan direstorasi. Hasil pemeriksaan klinis,model diagnostik dan gambaran radiografi menunjukkan bahwa gigi tersebut masih dapat dibuat restorasi berupa mahkota pasak konstruksi satu unit. Selanjutnya pasien dirujuk ke endodontis untuk dilakukan perawatan saluran akar (Gambar 1).

\section{PENATALAKSANAAN}

Setelah perawatan saluran akar, preparasi pasak dilakukan seperti prosedur biasa dengan penampang saluran akar oval untuk mencegah rotasi pasak, dan panjangnya $2 / 3$ panjang saluran akar atau sepanjang mahkota gigi kontralateral (Gambar 2A). ${ }^{2,3}$

Proses selanjutnya adalah pembuatan pola pasak menggunakan resin otopolimerisasi. Sebuah pin plastik dengan diameter yang sesuai dengan diameter preparasi saluran akar disiapkan.Monomer dan polimer resin otopolimerisasi dicampur, lalu diaplikasikan sepanjang pin plastik dan dimasukkan ke dalam ruang preparasi saluran akar yang telah dibasahi atau dilembabkan dengan air (Gambar 2B). Setelah beberapa saat, resin otopolimerisasi mengeras, kemudian pin plastik beserta resin yang sudah setting dikeluarkan dari saluran akar. Periksa hasil cetakan dan pastikan tidak ada porus atau bagian dinding saluran akar yang tidak tercetak.

Jika hasil cetakan pola pasak sudah baik, tambahkan campuran monomer dan polimer resin otopolimerisasi pada bagian korona pola pasak dan biarkan bentuknya tidak beraturan, lalu masukkan pola pasak tersebut ke dalam saluran akar hingga posisinya tepat. Sebelumnya, pastikan tidak ada resin otopolimerisasi berlebih yang masuk ke daerah undercut gigi-gigi sebelahnya sehingga pola pasak dapat dikeluarkan atau dimasukkan dalam satu arah pemasangan.Setelah resin otopolimerisasi mengeras, potong kelebihan pin plastik lalu periksa ketinggian resin bagian korona hingga kira-kira setinggi dataran oklusal (Gambar 3). 

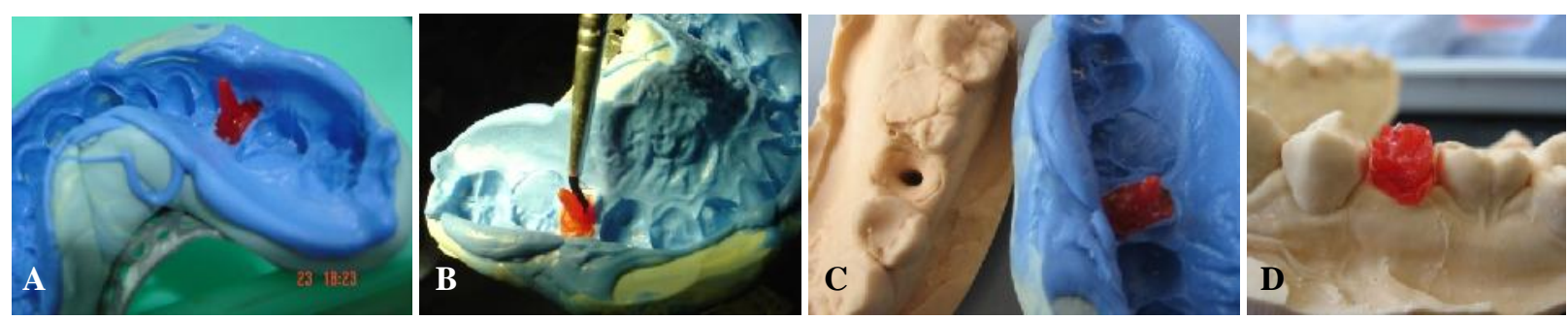

Gambar 4 Hasil cetakan pola pasak dengan bahan cetak elastomer, B aplikasi selapis tipis bahan pemisah pada pola pasak, $\mathbf{C}$ model gips dan cetakan, $\mathbf{D}$ pola mahkota pasak satu unit pada model kerja.
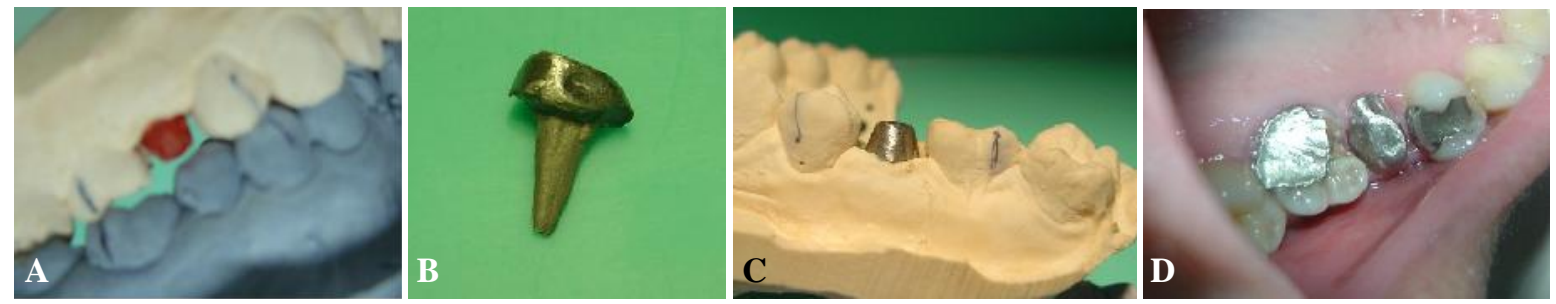

Gambar 5A Bagian koronal pola mahkota pasak yang telah dibentuk, B hasil tuangan pola mahkota pasak, C pasak hasil tuangan pada model kerja, D uji coba mahkota pasak dalam mulut pasien.
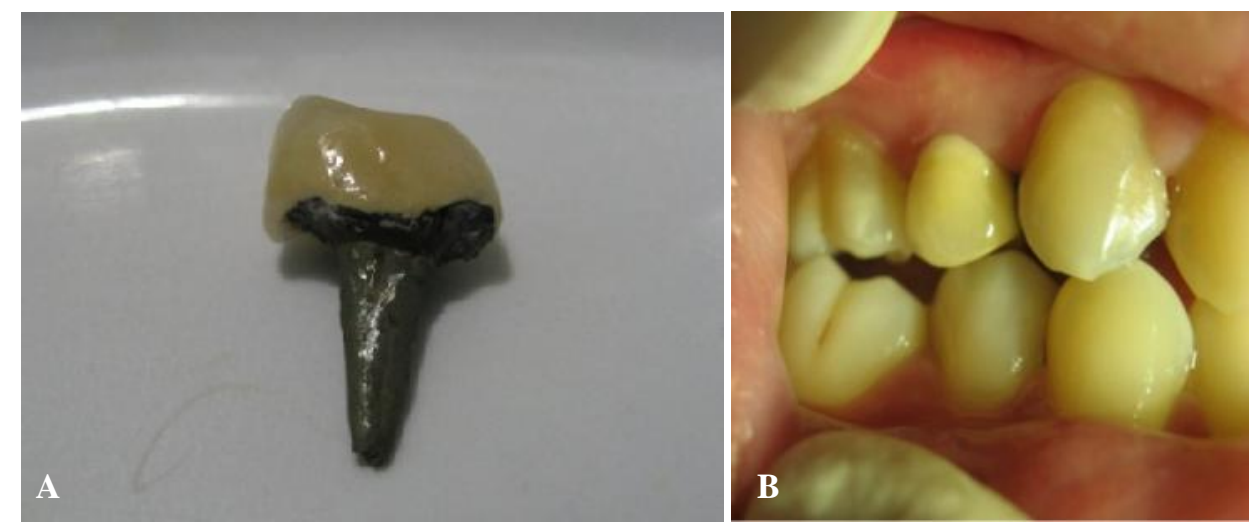

Gambar 6A Mahkota pasak yang sudah jadi, B Mahkota pasak dalam mulut pasien

Masukkan pola pasak hingga mencapai posisi semula, kemudian dilakukan pencetakan dengan bahan cetak elastomer (Gambar 4A). Sebelum cetakan diisi dengan gips keras, aplikasikan selapis tipis bahan pemisah pada pola pasak kemudian lakukan pengecoran dengan gips keras (Gambar 4B,C,D).

Selanjutnya dilakukan pembentukan resin pada bagian koronal sehingga menyerupai bentuk preparasi mahkota jaket vital, dilanjutkan dengan prosedur uji coba pola tersebut dalam mulut pasien dan jika telah sesuai, dilakukan penuangan logam pasak tersebut (Gambar 5A,B,C). Setelah pasak tuangan selesai, pasak tuangan diuji coba dalam rongga mulut. Setelah pasak pas pada saluran akar, dan bagian korona menyediakan ruangan yang adekuat untuk pelapis estetis porselen, pasak tuangan dikirim ke laboratorium dental untuk dilakukan pelapisan dengan bahan porselen sesuai dengan warna yang dipilih (Gambar 5D).
Setelah inti selesai dilapis dengan porselen, lakukan pemeriksaan di mulut seperti prosedur pembuatan mahkota jaket metal porselen yang biasa, kemudian restorasi disemen (Gambar 6A,B).

\section{PEMBAHASAN}

Restorasi mahkota pasak pada umumnya dibuat pada gigi dengan kerusakan mahkota yang sangat luas atau pada gigi yang telah dirawat saluran akar. Pada umumnya restorasi mahkota pasak yang dibuat berupa konstruksi dua unit, yaitu inti yang berpasak dan mahkota yang nantinya disemen pada inti tersebut., ${ }^{2,4}$ Konstruksi dua unit ini memberikan keuntungan jika dibandingkan dengan konstruksi satu unit, diantaranya adalah pada konstruksi dua unit jika restorasi mahkotanya ingin diganti tidak perlu melepas pasak dari saluran akar, dan adaptasi pinggiran mahkota terhadap permukaan akar dan posisi mahkota terhadap gigigigi tetangganya serta gigi antagonisnya tidak 


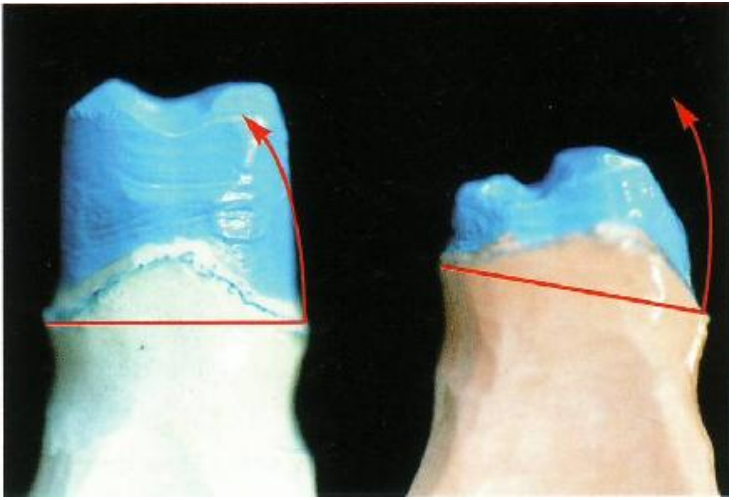

Gambar 7 Ilustrasi yang menunjukkan bahwa jarak dari akhiran preparasi ke tepi oklusal sangat berpengaruh terhadap retensi restorasi mahkotanya (Sumber: Sullivan M. Fixed prosthodontics in dental practice.London: Quintessence Publishing Co; 2005. p.7,140-9).

bergantung pada keakuratan dari pasak dengan saluran akar. ${ }^{2,4}$

Pada kasus pasien ini pembuatan mahkota pasak konstruksi dua unit bukan pilihan yang tepat karena ruangan serviko-oklusal gigi premolar yang direstorasi relatif pendek karena ekstrusi sehingga digunakan konstruksi satu unit. Jika mahkota pasak konstruksi dua unit dibuat pada gigi dengan jarak serviko-oklusal pendek dikhawatirkan restorasi mahkota di atasnya akan mudah lepas karena intinya hanya dapat dibentuk pendek saja, sehingga tidak mampu memberikan pegangan bagi mahkotanya.

Salah satu faktor yang berperan dalam retensi adalah panjang serviko-oklusal preparasi. Makin panjang inti akan makin retentif dan sebaliknya makin pendek inti makin tidak retentif. ${ }^{5}$ Sulivan menyatakan bahwa makin besar jarak dari akhiran preparasi ke tepi oklusal/insisal, maka restorasi ekstrakoronal makin sulit terlepas.Gaya-gaya tiping pada preparasi yang pendek akan menghasilkan gaya-gaya shear yang tidak dapat ditoleransi oleh semen luting, sementara pada preparasi yang tinggi akan menghasilkan beban kompresif pada semen luting yang lebih menguntungkan (Gambar 7). ${ }^{6}$

Martanto mengembangkan teknik mahkota pasak tuang berganda untuk merestorasi gigi geraham non-vital dengan ruangan mahkota yang pendek karena ekstrusi gigi. Prinsip restorasi ini adalah dengan mengecor bagian mahkota langsung terhadap pasak yang telah dibuat terlebih dahulu. Teknik ini lebih dikenal sebagai teknik cast-to, yang hasil restorasinya menyerupai mahkota pasak konstruksi satu unit. $^{2}$

Prinsip perawatan dalam laporan kasus ini adalah merestorasi gigi dengan mahkota pasak konstruksi satu unit. Cara pembuatan pola pasak secara langsung yang dikombinasi dengan cara tidak langsung, yang bertujuan untuk memperbaiki kekurangan konstrusi satu unit ini, yaitu kontak tepi restorasi mahkota terhadap permukaan akar sangat bergantung pada keakuratan pasak terhadap dinding saluran akar. ${ }^{2}$

Pembuatan pola pasak secara langsung dengan menggunakan resin autopolimerisasi menghasilkan suatu pola pasak dan cetakan tepi servikal gigi yang sangat akurat.Teknik pembuatan pola pasak dengan menggunakan bahan resin autopolimerisasi sudah lama diperkenalkan oleh beberapa penulis. ${ }^{1,3-7}$ Bahan cetak elastomer yang digunakan dalam pencetakan lengkung rahang untuk mendapatkan model kerja yang akurat.Pembentukan pola struktur korona sebagai inti yang nantinya akan dilapisi dengan porselen dilakukan tidak langsung pada model kerja sehingga lebih mudah pengerjaannya. Pada prinsipnya teknik pencetakan dan penggunaan bahan cetak pada kasus ini bertujuan mendapatkan model kerja dan hasil restorasi mahkota pasak konstruksi satu unit yang seakurat mungkin.

Jika dibandingkan dengan teknik mahkota pasak tuang berganda, teknik ini cukup sederhana, kunjungan pasien lebih sedikit, dan hasil restorasi merupakan satu kesatuan mahkota pasak tuang yang lebih kuat. Teknik kombinasi direct-indirect mempercepat tahap klinisnya dan mempermudah teknisi gigi membuat restorasi bagian korona yang ideal dan tetap mempunyai nilai estetis yang tinggi.

Dari penanganan kasus gigi premolar kedua rahang atas, disimpulkan bahwa mahkota pasak konstruksi satu unit merupakan pilihan yang tepat untuk merestorasi gigi dengan jarak serviko-oklusal yang pendek. Restorasi mahkota yang dibuat satu kesatuan tuangan logam dengan pasak memberikan retensi yang baik, bahkan menghasilkan restorasi dengan nilai estetis yang baik.

\section{DAFTAR PUSTAKA}

1. Grundy JR, Jones JG. A color atlas of clinical operative dentistry crowns and bridges. $2^{\text {nd }}$ Ed. London: Wolfe Publishing Ltd; 1992. p.110-1,128-32.

2. Martanto P. Teori dan praktek: Ilmu mahkota dan jembatan. Bandung: Alumni; 1982. hal.40-1; 74-8.

3. Shillingburg HT, Hobo S, Whitsett LD, Jacobi R, Brackett SE. Fundamental of fixed prosthodontics. $3^{\text {rd }}$ Ed. Kimberly Drive: Quintessence Pub. Co; 1997. p.202-6.

4. Rosentiel SF, Land MF, Fujimoto J. Contemporary fixed prosthodontis. $3^{\text {rd }}$ Ed. Philadelphia:Mosby;2001.p.298-301. 
5. Smith BGN. Clinical techniques in dentistry planning and making crowns and bridges. $2^{\text {nd }}$ Ed. London: Martin Dunitz Ltd; 1990. p.46.

6. Sullivan M. Fixed prosthodontics in dental practice. London: Quintessence Pub. Co; 2005. p.7,140-9.

7. Heilman ME. A simplified pattern for a cast metal post. J Am Dent Assoc 1998; 129: 223. 